\title{
Controladoria Estratégica como Suporte a Gestão e Competitividade: Uma perspectiva sobre o Balanced Scorecard
}

\author{
Ana Carla Dias de Lacerda ${ }^{\text {; }}$ Maria Erilúcia Cruz, Macedo ${ }^{2}$
}

\begin{abstract}
Resumo: O presente trabalho tem como tema "Controladoria estratégica como suporte a gestão e competitividade: uma perspectiva sobre o balanced scorecard", abordando inicialmente os conceitos de planejamento e gestão estratégica, para melhor entender a importância da controladoria dentro das organizações e paralelo a isso uma pesquisa de como o balanced scorecard pode ajudar as entidades a desempenhar uma gestão estratégica como suporte a tomada de decisão, a partir das suas perspectivas. Por conseguinte, buscou-se desenvolver de fato os conceitos e missão da controladoria e a importância do controle interno para que uma empresa possa aderir a controladoria estratégica. A metodologia que foi adotada para o desenvolvimento desse artigo foi a pesquisa bibliográfica, de caráter descritivo e por meio do método qualitativo, onde todas as informações foram estudadas em seus ambientes naturais.
\end{abstract}

Palavras-chave: planejamento estratégico, controladoria estratégica, balanced scorecard, tomada de decisão e diferencial competitivo.

\section{Strategic Controlling as Support for Management and Competitiveness: A Perspective on the Balanced Scorecard}

\begin{abstract}
The present work has as its theme "Strategic control as a support for management and competitiveness: a perspective on the balanced scorecard", initially approaching the concepts of strategic planning and management, to better understand the importance of control within organizations and parallel to this research of how the balanced scorecard can help entities to perform strategic management to support decision making from their perspectives. Therefore, we tried to develop in fact the concepts and mission of the controller and the importance of internal control so that a company can adhere to the strategic controller. The methodology that was adopted for the development of this article was the bibliographical research, of descriptive character and through the qualitative method, where all the information was studied in its natural environments.
\end{abstract}

Key words: strategic planning, strategic controller, balanced scorecard, decision making and competitive differential.

\section{Introdução}

O cenário econômico no Brasil tem sofrido mudanças cada vez mais constantes e frenéticas, fazendo com que as empresas percam o seu próprio controle para acompanhar a evolução do mercado.

\footnotetext{
${ }^{1}$ Graduanda do Conclusão do Curso de Bacharel em Ciências Contábeis - UNILEÃO. anna-lacerda1 @ hotmail.com

${ }^{2}$ Orientadora. Administradora. Curso de Bacharel em Ciências Contábeis - UNILEÃO . erilucia@ leaosampaio.edu.br 
Nesse sentido, se faz necessário um estudo de como as empresas podem acompanhar o mercado e consequentemente a competitividade acirrada, com a ajuda da controladoria que segundo Padoveze (2013, p. 37) "é responsável basicamente pelo sistema de informação contábil gerencial da empresa, e assegurar o resultado da companhia é a sua função".

A controladoria tem um importante papel dentro das organizações, e quando tratada como uma unidade administrativa, ela é um apoio para a gestão dos negócios dessa organização, atuando assim como suporte a tomada de decisão mais coesa e assertiva além de guiar a continuidade da organização com foco na inovação, competitividade e redução de custos para o aumento dos resultados econômicos. São por estes motivos que a controladoria vem fazendo parte da estrutura organizacional das empresas, e é através de seus procedimentos que ela poderá fornecer informações úteis e em tempo hábil, para assim garantir a continuação das operações organizacionais.

Diante do impasse que as empresas vêm sofrendo com o aumento da competitividade, surge então a necessidade de implantação de um plano estratégico para gerenciar os recursos que as empresas detêm para que seus resultados possam ser maximizados. Esses resultados podem ser alcançados com a implantação do Balanced Scorecard, que Kaplan e Norton (1997) defendem como sendo um sistema ou metodologia que possibilita a alta administração interpretar os objetivos do planejamento estratégico sobre uma lógica que adequa os indicadores de desempenho sobre quatro perspectivas, sendo elas classificadas como: perspectivas financeiras, perspectivas de clientes, perspectiva de processos internos e perspectivas de aprendizagem e crescimento.

Portanto, a presente pesquisa tem como objetivo geral verificar e compreender a relevância da controladoria estratégica para a organização dentro do mercado competitivo, se utilizando assim da ferramenta de gestão do Balanced Scorecard. Como objetivos específicos, determinou-se: conceituar e entender planejamento e gestão estratégica, identificar a importância do balanced scorecard e suas perspectivas como apoio a tomada de decisões, descrever a controladoria estratégica bem como a sua missão dentro das organizações e por fim ressaltar a importância do controle interno para a implantação do balanced scorecard e obter uma gestão estratégica eficaz.

Para o desenvolvimento do trabalho, foi utilizado como embasamento literário referencias e informações coletadas através da pesquisa bibliográfica de caráter descritivo, sobre os estudos de autores a partir de materiais publicados em livros e artigos.

Como medida a ser tomada pela gestão, é viável que a mesma adote o uso da controladoria estratégica com a implantação do balanced scorecard, para assim desempenhar 
melhor as funções administrativas e operacionais que consequentemente obterá a otimização dos resultados e maximização de seus lucros.

\section{Fundamentação Teórica}

\section{Planejamento e Gestão Estratégica}

A gestão estratégica faz parte de uma área da controladoria, denominada Controladoria Estratégica, que nos últimos tempos vem ganhando cada vez mais espaço dentro das organizações, no que se refere a um papel fundamental de não comprometer a continuidade da empresa no atual ciclo empresarial que está determinado pela questão da competitividade.

Para Wagner (2013), gestão estratégica consiste em um conjunto de práticas e objetivos, os quais são definidos pelos principais gestores de uma empresa, levando em consideração o ambiente interno e externo da organização. Esses objetivos traçados são de fundamental importância para que as empresas consigam materializar suas metas.

Segundo o pensamento de Oliveira (2001), no planejamento estratégico é indispensável apresentar uma visão integrada e absoluta da empresa. O que quer dizer que, a empresa deve ser analisada estrategicamente como um todo, conhecendo assim seus setores de atividades, para assim definir metas e serem direcionadas a obtenção dos resultados.

Conforme afirma Padoveze, (2012, p.101), “planejar é uma estratégia para aumentar as chances de sucesso de uma empresa em um mundo de negócios que muda constantemente". O que pode-se entender que o planejamento estratégico tem um papel importante dentro das organizações, que é planejar de forma eficaz a conduta da empresa de tal forma a não comprometer o andamento dos negócios. Ainda diante do mesmo pensamento, Padoveze afirma que o planejamento estratégico deverá ser eficaz e que o foco da controladoria estratégica é primordial que seja o planejamento estratégico.

Padoveze (2010), afirma que o planejamento estratégico além de ser a fase inicial do ciclo de gestão estratégica, é também a delimitação de um plano que interliga um plano a longo prazo ou situação a qual se deseja a um cenário atual da organização.

Para Bezerra (2014), o Planejamento Estratégico é uma metodologia pela qual se analisa uma organização sob diversos aspectos, conduzindo suas diretrizes e monitorando suas ações. O monitoramento e controle são resultados práticos da utilização do que conhecemos como plano estratégico. Em tese, o planejamento estratégico pode ser entendido como uma 
metodologia gerencial das organizações, na qual deve ser estabelecida um caminho a ser trilhado pela organização, buscando alinhar os objetivos e metas propostas pela alta administração. Esse planejamento deve ser composto de Missão (objetivo fundamental da empresa), Visão (meta a longo prazo), Valores (cultura e prática organizacional de uma empresa), Objetivos (são os resultados essenciais que a empresa deve atingir) e Estratégia (que são ações de médio e longo prazo a ser cumprido dentro da organização).

De acordo com Bezerra (2014, p. 01), a Gestão Estratégica é

\begin{abstract}
Um processo contínuo e integrado que visa auxiliar a administração no gerenciamento da organização e se baseia em três pilares fundamentais, que são: o planejamento estratégico, a execução estratégica e o acompanhamento da estratégia. O planejamento estratégico, como fora explicado acima, trata do estabelecimento da diretriz organizacional, ou seja, a missão, visão e os objetivos da empresa. Já a execução da estratégia se trata da conversão do curso de ação escolhido para o alcance dos objetivos, por meio dos projetos e processos. Por fim, o acompanhamento estratégico cuida da monitoração e avaliação do processo da gestão estratégica, visando melhora-lo e assegurando de forma concreta que tudo ocorra conforme planejado.
\end{abstract}

O planejamento estratégico deve pôr-se no mesmo nível da missão e valores da empresa, como também é o responsável pela elaboração dos objetivos e dos programas de ação para seu cumprimento, enquanto a gestão estratégica elabora as medidas que acompanham, controlam e faz as correções, quando necessário, para manter controle das variáveis que possam a vim a influenciar nos resultados obtidos pelas ações propostas no planejamento.

\title{
Balanced Scorecard
}

À proporção que a esfera empresarial e o mercado competitivo vem sofrendo mudanças, é necessário que se criem novos propósitos para que as organizações consigam sobreviver. E foi pensando nessas mudanças significativas do mercado que Balanced Scorecard, também muito conhecido pela sua sigla BSC foi elaborado pelos estudiosos David Norton e Robert Kaplan da universidade de Harvard.

Kaplan e Norton (1997), definem o Balanced Scorecard como sendo um sistema ou procedimento que possibilita a gestão interpretar os objetivos estratégicos da organização em um agrupamento lógico e adequado de indicadores de desempenho incorporado sobre quatro perspectivas, estando elas assim pertencentes a: finanças, conhecimento dos clientes, processos internos e aprendizagem e crescimento. Todos esses fatores advêm da necessidade de novos parâmetros para a análise do desempenho organizacional, se utilizando de informações que 
realmente sejam relevantes para a gestão e assim as decisões tomadas poderão ser mais assertivas.

Seguindo o mesmo raciocínio dos autores Kaplan e Norton (1997), Ramos (2018) consegue identificar o Balanced Scorecard como sendo uma metodologia que está direcionada para o gerenciamento da estratégia das organizações e tem como objetivo fazer com que os gestores da organização e sua própria equipe de colaboradores possam trabalhar sempre afim de conquistar metas a longo prazo, e assim comprometendo-se a concretizar as ações traçadas, que assim garantem um crescimento sólido e competitivo as empresas do mercado. Nesse sentido, o balanced scorecard atua na organização de forma eficiente para que sua visão seja concretizada, e consequentemente, sempre gerenciando os objetivos a longo prazo que foram implantados pela gestão.

Segundo Padoveze (2010), o balanced scorecard é um sistema de informação que gerencia a estratégia empresarial, assim retratando a missão e a estratégia da organização em um complexo de medidas de desempenho que tanto podem ser financeiras como não financeiras, e que consequentemente irá auxiliar a gestão estratégica. Isso se concretiza devido a projeção de unir a visão estratégica traçada pela gestão com as fases da aplicação e controle do processo de gestão empresarial, porque para Kaplan e Norton o que não é medido não é gerenciado.

Conforme o que afirma Bezerra (2014), ele analisa o balanced scorecard como sendo uma ferramenta que apresenta a estratégia da empresa por meio de um mapa, onde no mesmo é alinhado os objetivos da gestão e as medidas de desempenho que a empresa detém, oferecendo o detalhamento da estratégia de diferentes perspectivas.

Portanto, o Balanced Scorecard analisado como complemento das medidas de desempenho, sendo estas financeiras ou não, poderá sim, ser implementada nas empresas como uma ferramenta eficaz no desenvolvimento do papel da gestão para alcançar as metas propostas no plano estratégico.

Diante disso, torna-se necessário que o balanced scorecard seja apresentado e analisado nas organizações como uma metodologia e ferramenta de controle que detém grande importância nas tomadas de decisões, que com o passar do tempo o seu uso vem se tornando mais honroso quando se trata do seu conceito inicial de medir o desempenho. 


\section{As 4 Perspectiva do Balanced Scorecard (BSC)}

O balanced scorecard, além de evidenciar o alcance dos objetivos das organizações, ele também é equilibrado sobre pilares que lhes dão sustento e faz com que as metas organizacionais a longo prazo sejam bem alinhadas aos objetivos que foram traçados no plano estratégico.

Sobre o pensamento de Padoveze (2010), o balanced scorecard tem causas e efeitos devido as estratégias lançadas pela gestão, pois ele procura medir o desempenho das empresas sob quatro perspectivas, que estão explicitas no mesmo como sendo: financeira, do cliente, dos processos internos da empresa e do aprendizado e crescimento.

Para Bezerra (2014). O balanced scorecard revela vetores que as empresas necessitam apresentar um bom desempenho financeiro e competitivo para que o mercado não lhe exclua, e assim, sua estrutura é formada por quatro perspectivas, sendo elas alinhadas como: Financeira, Clientes, Processos internos e Aprendizagem e crescimento. Bezerra (2014) ainda ressalta a ideia do balanced scorecard, que é a de propor e fornecer uma visão do desempenho globalizada sobre essas quatro perspectivas.

Abaixo, segue uma imagem que mostra detalhadamente o processo de desempenho das quatro perspectivas do balanced scorecard.

Figura 1. Perspectivas do Balanced Scorecard:

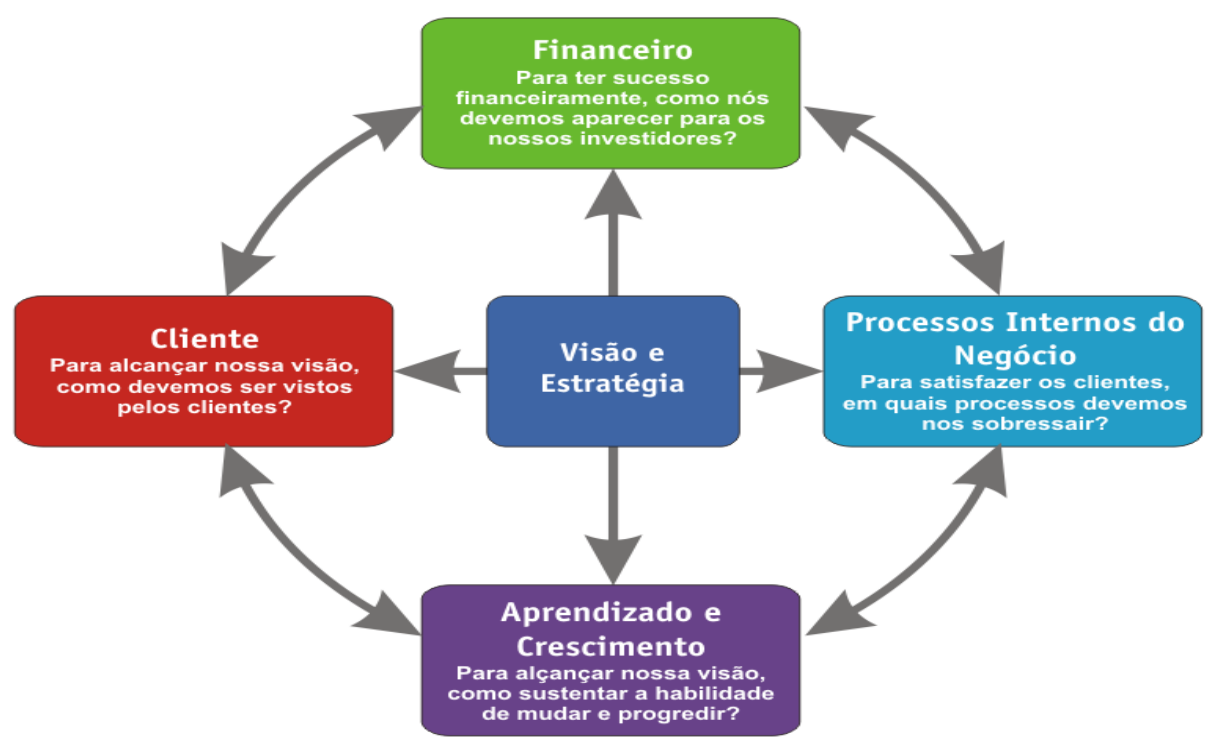

Fonte: Kaplan e Norton(1997) 
Como mostra a imagem acima, o balanced scorecard pode ser analisado sob quatro perspectivas, as quais seguem abaixo o estudo desse contexto que define aonde a organização pretende chegar e ocupar um determinado espaço no mercado.

\section{Perspectiva Financeira}

Os indicadores e metas essenciais que são estabelecidos nessa perspectiva, estão diretamente ligados com o crescimento e variedades das receitas, a melhoria de produtividade, redução de custos, aplicação dos seus ativos, Cabral (2016).

Oliveira (2015), analisa essa perspectiva financeira como sendo os objetivos que tendem a garantir um retorno aos investimentos efetuados na empresa. E para isso, os objetivos financeiros devem estar alinhados ao planejamento estratégico. São indicadores que afirmam como as empresas querem ser vistas pelos acionistas e qual sua capacidade de pagamento.

Gusmão e Batista (2010), vem para concordar que estes indicadores mostram se a implementação e prática dessa estratégia estão de alguma forma contribuindo para a melhoria dos resultados da empresa. Geralmente os objetivos da perspectiva financeira se correlacionam com a rentabilidade, o crescimento financeiro que retorna aos acionistas.

\section{Perspectiva de Clientes.}

Para Bezerra (2014), essa perspectiva está principalmente ligada a visão da empresa e ao seu negócio como um todo, monitorando assim, como a empresa está entregando valor ao cliente, por se tratar de indicadores de satisfação, nessa perspectiva.

As medidas de resultado dessa perspectiva, são aquelas que refletem metas para as operações que envolvem o marketing, a logística e o desenvolvimento de produtos e serviços da empresa, (CABRAL, 2016), são eles: 
Quadro 1: Medidas de resultado

\section{Medidas de Resultado}

\begin{tabular}{|c|c|}
\hline Participação de mercado & $\begin{array}{l}\text { Participação da empresa em determinado ramo de negócios ou } \\
\text { mercado. }\end{array}$ \\
\hline Captação de clientes & $\begin{array}{l}\text { Trabalha a forma de como os novos clientes vão ser } \\
\text { conquistados. }\end{array}$ \\
\hline Retenção de clientes & $\begin{array}{l}\text { Se refere ao quesito de como a empresa vai manter um bom } \\
\text { relacionamento com os clientes fidelizados. }\end{array}$ \\
\hline Satisfação dos Clientes & $\begin{array}{l}\text { É a satisfação que os clientes possuem em relação aos critérios } \\
\text { específicos da empresa e da proposta de valor. }\end{array}$ \\
\hline Lucratividade dos clientes & $\begin{array}{l}\text { É o lucro que a empresa obtém, depois de deduzir as despesas } \\
\text { para manter o cliente dentro da empresa. }\end{array}$ \\
\hline
\end{tabular}

Fonte: Adaptado de Cabral (2016)

\section{Perspectiva dos Processos Internos}

Sobre o que pensa Oliveira (2015), são esses processos internos que agregam valores aos produtos e serviços de uma empresa, por isso, consistem em identificar e mapear os processos essenciais para a realização dos objetivos da organização, consequentemente implementando sobre estes indicadores o processo de gestão de melhoria contínua.

Se tratando ainda da perspectiva dos processos internos, para Bezerra (2014), é nessa perspectiva que a gestão pode identificar e rever novos caminhos para melhorar a execução do planejamento da empresa diante dos clientes e acionistas, já que nessa fase pode-se identificar os processos críticos para a realização dos objetivos e das metas anteriormente traçadas no planejamento estratégico.

Gusmão e Batista (2010), vêm para reafirmar que estes indicadores devem refletir sobre os processos organizacionais que realizam maior impacto sobre a satisfação dos clientes. Assim, as empresas precisam empenhar-se no que tange a mensuração das competências essenciais para assegurar a liderança no mercado.

\section{Perspectiva de Aprendizagem e Crescimento}

Para Oliveira (2015), é nessa perspectiva em que a gestão faz uma minuciosa análise, da qual se possa identificar qual a estrutura a organização pode e deve receber aplicações de recursos, visando o crescimento da empresa a médio e longo prazo, buscando investir em infraestrutura, equipamentos, novos produtos e serviços e capacitação dos recursos humanos. 
De acordo com Cabral (2016), o objetivo dessa perspectiva tem como base a identificação da infraestrutura, a qual deve ser construída para gerar e agregar melhoria e crescimento no longo prazo, contribuindo assim para a criação de condições as quais podem levar a realização dos objetivos das demais perspectivas. $\mathrm{O}$ autor faz destaque a valorização do capital humano, que para ele, é gerador de novas estratégias e inovação de produtos ou serviços para as empresas. Deve-se ser analisado três eixos nessa perspectiva:

1. Capacidade dos funcionários: o conhecimento dos funcionários acarreta a mudança e inovação da empresa.

2. Capacidade dos sistemas de informação: o mercado competitivo requer dos colaboradores informações de seus clientes e a consequência financeira de suas decisões.

3. Motivação e alinhamento: a motivação e iniciativa dos funcionários devem ter contribuição fundamental do clima organizacional. Visa ainda, unir os ativos que criam o valor da empresa.

Kaplan e Norton (1997), afirma que, para nortear a gestão no processo de montagem da perspectiva de aprendizado e crescimento, seja utilizado a pergunta: "para alcançarmos nossa visão, como sustentaremos a nossa capacidade de mudar e melhorar? ", porque o aprendizado e crescimento tem base sobre três pontos principais, que são pessoas, sistemas e procedimentos organizacionais.

Portanto, fica evidente a importância que essas perspectivas trazem a empresa, uma vez que a elas são agregadas a visão, os valores e o entendimento para o desenvolvimento e aplicação do balanced scorecard dentro das organizações, buscando assim, gerar crescimento e melhorias no alcance dos objetivos.

\section{Balanced Scorecard Como Apoio a Tomada de Decisão}

Oliveira (2015), ressalta a importância do uso do balanced scorecard como ajuda na tomada de decisão, em razão aos benefícios que o BSC traz, que podem ser definidos como sendo: 1) converte estratégia em objetivos, e objetivos em ações efetivas; 2) dá aos gestores uma visão ampla e sistematizada do desempenho operacional da organização; 3) é um processo constante de mensuração e atualização de planos e metas; 4) facilita e otimiza a comunicação 
interna e externa da organização; 5) permite desenvolver uma cultura de aprendizagem e uma melhoria contínua.

Para Bezerra (2014), para que os objetivos do BSC sejam alcançados, é necessário que se desenvolvam algumas ações, que podemos relacionar como sendo:

1. Esclarecer e traduzir a visão estratégica: o BSC ajuda a esclarecer quais ações devem ser tomadas através de um mapa estratégico, diante das relações causa e efeito, que muitas vezes as empresas não possuem essa visão esclarecida.

2. Planejar, estabelecer metas e alinhar as iniciativas estratégicas: aqui se estabelece a definição de metas e objetivos para os colaboradores.

3. Melhorar o feedback e o aprendizado estratégico: é a revisão e avaliação do desempenho das metas e das estratégias escolhidas pela gestão. Essa ação otimiza o conhecimento dos colaboradores e suas habilidades. É entendido como um acompanhamento da organização.

4. Comunicar e associar objetivos e medidas estratégicas: fazer com que os gestores se assegurem de que todos os níveis da organização compreendem os comandos e estratégias a longo prazo. Nessa ação, é interessante que os gestores façam com que seus colaboradores se sintam capacitados a atingir as metas que lhes foram impostas.

Portanto, o que se pode afirmar é que o balanced scorecard se tornou uma ferramenta de gestão estratégica devido ao sucesso que ele tem causado dentro das organizações buscando alinhar o planejamento estratégico as atividades operacionais que a organização desenvolve. Com base nas referências que se tem, é notável a relevância do uso do balanced scorecard como um apoio a tomada de decisão da organização, já que essa metodologia ou sistema consegue analisar minuciosamente o cenário ou situação da organização de uma forma ampla e globalizada, o que facilita aos seus gestores uma análise e conclusão assertiva diante dos objetivos e resultados esperados.

\section{Controladoria}

A tecnologia está cada vez mais avançada, e com isso as empresas estão sempre em busca de novos caminhos, que não comprometam a sua continuidade.

Conforme Schmidt e Santos (2009), a controladoria tem sua origem ligada ao processo de evolução dos meios sociais e de produção, que tiveram grande influência com o advento da 
revolução industrial. Foi depois da revolução industrial que as organizações se tornaram mais complexas e o aumento de fluxo de capital dispararam, fazendo com que houvesse um progresso e crescimento nas relações governamentais.

Schmidt, Santos e Martins (2014), concluem que o aumento no número de fontes de capitais foi um dos marcos mais importantes que concretizou o surgimento da controladoria, onde as empresas tiveram a necessidade, especialmente depois da quebra da Bolsa de Valores de Nova York em 1929, o que ocasionou grande abalo na confiabilidade das demonstrações contábeis por parte dos seus usuários.

Confirmando o pensamento, as organizações tiveram um crescimento significativo após a revolução industrial na Inglaterra, e foi a partir do século XIX que a contabilidade ganhou mais importância, e consequentemente a controladoria, que vem obtendo grande destaque nos cenários econômicos das organizações.

\section{Conceitos}

Conforme Padoveze (2010, p.3), “A controladoria é a utilização da ciência contábil em toda sua plenitude". A ela cabe ser entendida como a ciência contábil evoluída.

Para Mosimann e Fisch (1993), a controladoria pode ser entendida como uma doutrina e conhecimentos que se relacionam com a gestão econômica, podendo assim ser visualizada sob dois enfoques que são definidos como: a) entendida como um órgão administrativo que possui missão, função e princípios que são definidos no modelo de gestão; b) entendida como uma érea ou esfera do conhecimento, a qual detém fundamentos, conceitos, princípios e métodos que advém de outras ciências.

Tomando como referencial a definição dos autores Mosimann e Fisch (1993, p. 96)

\footnotetext{
Sob esse enfoque, a controladoria pode ser conceituada como o conjunto de princípios, procedimentos e métodos oriundos das ciências da administração, economia, psicologia, estatística e principalmente da contabilidade, que se ocupa de gestão econômica das empresas, com o fim de orientá-las para a eficácia.
}

Nessa visão, a controladoria pode ser identificada como autônoma e não se confunde com as demais, como por exemplo a contabilidade, apesar de se utilizar bastante das informações contábeis para desenvolver seu papel dentro das organizações.

Oliveira, Perez Jr. e Silva (2015), destaca que a controladoria é um departamento da organização, o qual se responsabiliza pelo projeto, elaboração, implementação e manutenção 
do sistema integrado das informações operacionais, financeiras e contábeis das entidades, podendo ser com finalidade lucrativa ou não. O conceito vem para destacar a função principal da controladoria enquanto administradora de informações.

Instigado pelo pensamento dos autores Oliveira, Perez Jr. e Silva (2015), Mosimann e Fisch (1993) e Padoveze (2010), a controladoria pode ser olhada sob duas linhas, uma pode ser como ciência que possui princípios norteadores, e outra como um departamento de uma organização que busca alcançar metas traçadas pela gestão. Assim, ela deve ser vista como ramo do conhecimento responsável por estabelecer bases conceituais e como órgão administrativo de uma organização que se responsabiliza pelo planejamento estratégico.

\section{Função da Controladoria dentro da organização}

Com o passar dos anos, o uso da controladoria vem se tornando bastante requisitada dentro das organizações, principalmente no que diz respeito a sua influência no processo de tomada de decisão.

Conforme Oliveira, Perez Jr. e Silva (2015), o papel da controladoria é prestar auxílio e colaborar com a gestão empresarial, contribuindo com mensurações de alternativas econômicas para empresa, que através da visão sistêmica da possa integrar informações e reportá-las para facilitar o processo decisório. Isso tudo se acontece porque o processo decisório é influenciado diretamente pela ação da controladoria, por meio de informações úteis que dão apoio ao planejamento e controle.

Diante do cenário globalizado ao qual as organizações estão inseridas, Schmidt, Santos e Martins (2014) destaca funções muito relevantes dentro da controladoria, que podem ser identificadas como:

a) Estabelecer, guardar e sistematizar um plano de operação consistente com os objetivos da empresa.

b) Gerenciar os riscos operacionais através da administração dos sistemas internos.

c) Preparar, analisar e explicar o que será disponibilizado no sistema de informações que será a base para os gestores, em casos de tomada de decisão, a preparação dos relatórios de demonstração servirá para acionistas, governo, instituição financeira e fornecedores.

d) Desenvolver, estabelecer e manter sistemas de contabilidade societária, de custos e gerencial para todos os níveis da empresa, para que o registro de atividades se 
adequem ao controle interno e se flexibilizem para fornecer as informações necessárias para a gestão da organização.

e) Supervisionar os impostos das esferas, municipais estaduais e federais, e internacionais quando for o caso, para que seja mantido o relacionamento com os agentes e autoridades governamentais. Supervisionar também as funções da tesouraria é uma tarefa importante para o departamento da controladoria.

Em se tratando das funções da controladoria, Padoveze (2010) destaca que ela tem como função precípua a responsabilidade pelo processo de gestão da organização do planejamento estratégico e operacional, e tendo ainda que auxiliar as demais atividades que a empresa desempenha em seu processo de gestão.

Os autores Oliveira, Perez e Santos (2015), vem para confirmar que a controladoria tem funções que são a base para o desenvolvimento de suas atividades dentro da empresa, e podem ser distribuídas como:

a) Informação: corresponde a três sistemas (contábil, financeiro e gerencial).

b) Motivação: essa se refere aos efeitos do comportamento que está ligado aos sistemas de controle, o que de fato tem ligação com o instrumento de busca de melhores resultados na empresa;

c) Coordenação: centraliza as informações e para que o controller possa assessorar eventuais inconsistências dentro da organização e apresentar proposta para solução, visando assim orientar os diversos setores dentro da empresa sobre as adversidades existentes, e consequentemente buscando a solução;

d) Avaliação: é a fase de interpretação das informações, relatórios e fatos e consequentemente avaliar os resultados por área de responsabilidade ou por departamento da organização;

e) Planejamento: assessora a gestão na direção para a determinação dos planos e objetivos estratégicos. Nessa função a controladoria se propõe a auxiliar na formulação de estratégias que a empresa pode adotar e construir o plano estratégico;

f) Acompanhamento: verifica e controla e evolução e desempenho dos planos que foram determinados e mensurados a fim de corrigir as falhas existentes na organização, ou até mesmo de reformular os planos. É a verificação contínua das atividades realizadas e sua comparação com o que foi planejado. 
Portanto, é evidente que a controladoria agrega importantes funções dentro das organizações, pois ela atua no processo de gestão da organização nos níveis estratégicos e operacionais, os quais ajudam o melhoramento do desempenho das atividades e consequentemente a gestão poderá tomar uma decisão mais assertiva para garantir o sucesso da empresa.

\section{Missão da Controladoria}

Como todo e qualquer departamento de uma organização possui uma missão, a controladoria não é diferente, ela necessita de uma missão para desenvolver suas funções com mais precisão.

Para Padoveze (2010), a missão da controladoria é assegurar e suportar o processo de gestão da empresa através do seu sistema de informação, o qual deve dar apoio a gestão. Esse sistema precisa estar integrado com o sistema operacional da empresa e ter como característica principal a mensuração econômica das operações do planejamento, controle e avaliação dos resultados de desempenho dos gestores. Assim, para Padoveze (2010), a controladoria fica responsável pelo processo de assegurar a eficácia da empresa por meio do controle da das operações e seus resultados planejados e otimizados.

Conforme pensa os autores Oliveira, Perez e Santos (2015), a missão da controladoria é prestar assessoria contínua a alta administração, com o objetivo de contribuir com o aprimoramento e melhoramento organizacional através das críticas construtivas que o ajudem nesse sentido.

Nesse sentido, ainda com o passar dos anos Figueiredo e Caggiano (2017) ressalta que a missão da controladoria é zelar pela continuidade da organização, assegurando assim a otimização do seu resultado global. Portanto, pode-se concluir que a missão da controladoria também visa proteger os ativos da organização.

Entende-se que a missão da controladoria contribui de forma significativa para o desafio que a organização possui ao adentrar no mercado, pois ela ajuda a direcionar o seu processo de gestão visando retribuir com informações que dê total suporte para as possíveis tomadas de decisões. 


\section{Controle Interno}

Para que se entenda de fato o que seria a essência do controle interno, é necessário que tenhamos em mente o que o conceito de controle pode nos retratar.

Figueiredo e Caggiano (2017), afirma que o controle está diretamente ligado a função do planejamento, porque ele se propõe a assegurar que as atividades estejam sendo desenvolvidas conforme foi planejado.

O Instituto de Auditores Internos do Brasil- AUDIBRA (1992), busca traduzir o controle interno como sendo do uma ação ou decisão tomada pela administração, sejam elas entendidas pela alta administração ou pelos outros níveis gerenciais, que tem o intuito de acrescentar e estender a probabilidade de atingir os objetivos e metas organizacionais. Sobre esse enfoque a alta administração é quem está responsável pela gerência, planejamento, organização, direção e controle de desempenho, buscando assim possibilitar o alcance da realização das metas e objetivos.

Para Crepaldi (2013) controle interno é um sistema que a empresa possui e que compreende um plano de organização, atribuições e responsabilidades das medidas adotadas pela gestão para proteger os ativos, verificando assim a exatidão e fidelidade das informações e dados contábeis, e assim estimular o segmento das medidas administrativas estabelecidas.

Conforme Attiê (2010), controle interno está determinado por vários fatores, que ele descreve como sendo:

a) Plano de organização, que é método pelo qual um sistema pode ser organizado;

b) Os métodos e medidas que estabelecem os caminhos para se chegar a um determinado objetivo;

c) Visa a proteção do patrimônio, que pode ser compreendida pela forma como eles são defendidos e monitorados;

d) Exatidão e fidedignidade dos fatos contábeis que precisam estar de acordo com a observância dos princípios contábeis;

e) Eficiência operacional, que pode ser definida pela ação das transações realizadas pela empresa;

f) Políticas administrativas, que compreende o sistema de regras, princípios, condutas, normas e funções estabelecidas pela gestão para a obtenção de resultados. 
Para Schmidt (2009), o controle interno é analisado como sendo um conjunto de controles que se interligam de maneira lógica para abranger todas as funções administrativas organizacionais, que fazem parte do planejamento.

Attiê (2010), vem para trazer o controle interno para ser analisado/dividido sobre duas dimensões: o controle contábil e o controle administrativo, que abaixo podem ser descritos como sendo:

O Controle Contábil está relacionado com os métodos e procedimentos que garantem a integridade e proteção do patrimônio da empresa, buscando assim salvaguardar a propriedade dos registros contábeis. Um exemplo de controle contábil é a auditoria interna, os controles físicos dos ativos de uma organização e sistemas de registros.

O Controle Administrativo compreende as ações voltadas para a política de negócios da organização, incluindo assim os métodos e procedimentos que se relacionam com a eficiência das operações organizacionais. Um exemplo de controle administrativo é o treinamento do pessoal (equipe de colaboradores), o controle de qualidade dentro da organização e as análises das estatísticas da lucratividade da empresa.

Dessa forma, fica fácil perceber que o controle interno permeia todos os meios de planejamento que a empresa possui envolvendo todas as atividades e rotinas, sejam elas de natureza contábil ou administrativa, ambas com o intuito de organizar a empresa, assim cumprindo seus objetivos e resguardando seus ativos, trazendo benefícios para a gestão e servir como um instrumento de apoio para o alcance de metas.

\section{Controladoria Estratégica}

A controladoria estratégica vem ganhando cada vez mais prioridade dentro das organizações, principalmente no que diz respeito ao planejamento estratégico da empresa.

Para Padoveze (2012), a controladoria estratégica pode ser conceituada como sendo uma atividade da controladoria que através de um sistema de informação contábil, entrega informações tanto financeiras como não financeiras aos responsáveis pelo planejamento estratégico, assim apoiando o processo de análise, planejamento, implementação e controle da estratégia da empresa. Por isso, entende-se que o sistema de informação da controladoria estratégica deve está necessariamente alinhada com as estratégias da entidade. 
Thompson (1995) apud Padoveze (2014) conclui que a estratégia organizacional possui três níveis e podem ser relacionados como: Estratégia Competitiva, Estratégia Funcional e Estratégia Corporativa.

Quadro 2: Níveis da estratégia organizacional

\section{NÍVEIS DA ESTRATÉGIA ORGANIZACIONAL}

\begin{tabular}{|l|l|}
\hline Estratégia & $\begin{array}{l}\text { São as estratégias empresariais como um todo, influenciadas } \\
\text { principalmente pelas decisões que a empresa toma para } \\
\text { competir no mercado, relacionando-se assim com criação e } \\
\text { manutenção da vantagem competitiva. }\end{array}$ \\
\hline $\begin{array}{l}\text { Estratégia } \\
\text { Funcional }\end{array}$ & $\begin{array}{l}\text { São as estratégias elaboradas para cada área/setor da } \\
\text { organização, com isso, elas se relacionam umas com as outras, } \\
\text { permitindo que as estratégias competitivas sejam } \\
\text { implementadas. }\end{array}$
\end{tabular}

$\begin{array}{ll}\text { Estratégia } & \begin{array}{l}\text { Essa estratégia define qual mercado/ramo a empresa vai atuar, } \\ \text { Corporativa }\end{array} \\ \text { decide quais são os negócios que a empresa deve participar e } \\ \text { quais produtos e serviços ele deve focar. }\end{array}$

Fonte: Adaptado de Padoveze (2014)

Para Fernandes (2018) a controladoria estratégica é a evolução da controladoria tradicional, que deixa de ter somente a função de controle e agora passa a pensar na estratégia do negócio, ajudando a gestão em como desenvolver ações para manter as vantagens competitivas já conquistadas pela empresa. Sendo este o seu conceito, podemos dizer que a controladoria estratégica está integrada ao processo de decisão da organização, pensando assim no seu futuro.

Conforme os autores Oliveira, Perz Jr. e Silva (2015), a estratégia da empresa está conceituada como uma forma de pensar no seu futuro, estando assim devidamente integrada ao processo de tomada de decisão. Para eles, a definição mais comum de estratégia é a de que ela é vista como um conjunto de ações orientadas para desenvolver e manter as vantagens competitivas organizacionais.

Nesse contexto, as empresas mantêm a controladoria estratégica principalmente para apoiar a gestão ao desenvolvimento e implementação da estratégia empresarial, fazendo que com o foco do negócio e a vantagem competitiva sejam mantidos.

Fernandes (2018) ainda volta a afirmar que as empresas que aderem à controladoria estratégica estão munidas de algumas vantagens, pois ela fornece informações básicas para que a organização tenha um bom desempenho e para que seu plano estratégico possa ser cumprido 
independentemente das adversidades que venham a ocorrer na empresa. Essas vantagens podem ser elaboradas como sendo:

$\checkmark$ Diagnóstico de deficiências que a empresa possui, como objetivo de reduzir os custos e aumentar a produtividade;

$\checkmark$ Identificar situações de progresso, estagnação ou recuo no andamento do negócio, assegurando a empresa e garantindo ganhos de competitividade e facilidade em atingir os objetivos planejados;

$\checkmark$ Reconhecimento das potencialidades dentro do mercado competitivo e aproveitamento das oportunidades que surgem de maneira eficientes;

$\checkmark$ Assegurar a empresa a otimização dos resultados dos processos internos e o aumento de que as decisões tomadas pela gestão sejam assertivas;

$\checkmark$ Prevenir a empresa de futuros desafios que o mercado competitivo poderá propor.

Portanto, a controladoria estratégica pensada como uma metodologia de planejar o futuro da empresa, espera-se que seus resultados sejam a verificados a longo prazo.

É notório que as empresas que querem estar inseridas no mercado competitivo e que também desejam manter a sua vantagem competitiva para não perder espaço no mercado, elas necessitam sim de um trabalho desenvolvido pela controladoria estratégica, visto que a gestão poderá tomar decisões mais confiantes e assertivas, e assim não comprometer a continuidade da empresa no mercado além de manter os benefícios que a controladoria pode assegurar a organização.

\section{Metodologia}

A metodologia vem para ajudar a explicar o processo da investigação científica. Para Minayo e Gomes (2012, p.14), a metodologia é "o caminho do pensamento e a prática exercida na abordagem da realidade".

Neste projeto, o intuito é apresentar a verificação e compreensão de relevância da controladoria estratégica para as empresas que desejam ter um diferencial competitivo, se utilizando assim do Balanced Scorecard, uma ferramenta para o desenvolvimento de uma gestão estratégica. 
Como exposto, a pesquisa pode ser classificada como sendo de natureza e finalidade básica em sua abordagem qualitativa que tem objetivos descritivos e procedimentos bibliográficos. Tudo isso, com base

Para que se entenda mais sobre a metodologia, a qual foi utilizada para desenvolver essa pesquisa, quanto ao objetivo Andrade (2010), diz que na pesquisa descritiva os fatos serão observados, registrados, analisados e interpretados sem que o pesquisador interfira nos resultados. São pesquisas geralmente desenvolvidas nas áreas das ciências humanas e sociais. Nessa pesquisa descritiva, como sugere o nome, ela busca concentrar na descrição de um objeto de estudo do pesquisador, para analisar e verificar se os resultados encontrados são favoráveis para o objeto, ou não.

Quanto a abordagem a pesquisa pode ser definida como sendo de abordagem qualitativa, que como afirma Takahashi, et all (2013) a pesquisa qualitativa, é em sua excelência um método que se constitui de uma abordagem, a qual busca compreender os fenômenos, sejam eles humanos ou sociais de uma forma naturalística e interpretativa, o que significa afirmar que os fatos devem ser estudados em seus ambientes naturais.

Sobre os procedimentos utilizados para desenvolver a pesquisa, eles podem ser classificados como sendo de caráter bibliográfico, como afirma Lakatos e Marconi (2009, p. 57), “a pesquisa bibliográfica não é a mera repetição do que já foi dito ou escrito sobre certo assunto, mas propicia o exame de um tema sob um novo enfoque ou abordagem, chegando a conclusões inovadoras". Sendo assim, cabe ao pesquisador propor um tema novo e desenvolver algo novo sobre aquilo que já foi escrito por outras pessoas, através da análise de literaturas sobre o assunto.

Como definido e com o intuito de atender o que se pede no presente artigo científico, a utilização da metodologia descritiva e exploração da pesquisa bibliográfica foi de fundamental importância para o desenvolvimento do mesmo, bem como os métodos utilizados, já descritos acima, que se classificam como sendo de abordagem qualitativa, fazendo com que o pesquisador busque compreender os fenômenos em sua naturalidade.

\section{Considerações Finais}

A controladoria possui um leque de ferramentas que ajudam e proporcionam aos gestores obter informações claras, úteis e tempestivas para subsidiar a gestão eficaz de qualquer organização. O cenário econômico em que se encontra o país, é imprescindível o uso de uma 
controladoria estratégica para que a organização possa manter um diferencial competitivo no mercado.

O presente trabalho buscou associar o uso da controladoria estratégica dentro das organizações, para que estas possam manter um diferencial competitivo dentro do mercado, buscando assim a ajuda do balanced scorecard e suas perspectivas, que de certa forma expõe ao gestor da empresa uma visão mais ampla e globalizada das ferramentas que a empresa possui para competir. O balanced scorecard é usado dentro da empresa como uma ferramenta ou metodologia responsável pelo gerenciamento estratégico para que os objetivos e metas da organização sejam concretizados.

Partindo do pressuposto de que a empresa precisa se manter no mercado a qualquer custo para jogar suas apostas no que ela faz e desenvolve de melhor, a controladoria estratégica é uma ferramenta que pode subsidiá-la quanto a gestão das estratégias a serem traçadas através de um plano estratégico a longo prazo analisado como um ciclo, contendo a missão, visão valores e objetivos da organização. Já dizia o autor Padoveze (2010) que as organizações que fazem o uso da controladoria estratégica têm mais chances de obter sucesso no caminho competitivo.

A controladoria estratégica é usada com o intuito de sempre está atualizando a organização em relação a concorrência e a criar algo novo, inclusive um diferencial para que possa ser copiado pelos demais concorrentes, e assim sucessivamente. É como ver a controladoria sobre um ciclo contínuo, que está sempre em aprimoramento e não existe um fim predeterminado, pois há sempre algo novo para ser criado e sugestões de melhorias empresariais para serem implantadas.

No que se faz referência ao balanced scorecard, pode-se ressaltar a importância do mesmo dentro da entidade, para um estudo globalizado e amplo das possibilidades que a empresa possui, convertendo assim as estratégias e objetivos, e estes por sua vez, podem ser convertidos em ações para o crescimento e melhoria no alcance de metas traçadas anteriormente no planejamento estratégico e concretização de resultados. O que fica evidente, é que o balanced scorecard se tornou, com o passar do tempo e implantação do mesmo nas organizações, uma ferramenta de gestão estratégica eficiente eficaz que consegue fazer com que os gestores analisem minuciosamente o cenário e a situação em que a empresa se encontra, e quais os recursos que essas têm disponíveis para que possam gerar crescimento, e consequentemente gerar lucratividade.

É notório que não se pode implantar o balanced secorecard sem que a empresa possua um controle interno eficaz. O controle interno é um mecanismo que as organizações possuem 
baseados em um plano organizacional, onde as atribuições e responsabilidades das medidas e regras foram tomadas pela gestão para melhor proteger os ativos da empresa e consequentemente verificar a exatidão do desenvolvimento das atividades operacionais.

Portanto, sugere-se a implantação da controladoria estratégica dentro das entidades, com a utilização através do balanced scorecard para melhor otimizar os resultados e maximizar os lucros, mantendo sempre um diferencial competitivo frente a sua concorrência.

\section{Referências}

ANDRADE, Maria Margarida de. Introdução a metodologia do trabalho científico. 10 ed. São Paulo: Atlas 2010.

ATTIE, William. Auditoria: conceitos e aplicações. 5 ed. São Paulo: Atlas, 2010.

AUDIBRA- Instituto de Auditores Internos do Brasil. Normas Brasileiras para o exercício da auditoria interna. 2 ed. São Paulo: Audibra 1992.

BEZERRA, Felipe. Balanced Scorecard (BSC): análise e aplicação. Disponível em: <http://www.portal-administracao.com/2014/03/o-que-e-balanced-scorecard-bsc.html >. Acesso em 21 set 2018 .

O que é planejamento e gestão estratégica? Disponível em: $<$ http://www.portaladministracao.com/2014/06/planejamento-gestao-estrategica-o-que-e.html >. Acesso em 15 set 2018

CABRAL, Igor Vovchenco. Perpectivas do Balanced Scorecarde (BSC). Acesso em:< https://pt.linkedin.com/pulse/perspectivas-do-balanced-scorecard-bsc-igor-vovchenco-cabral >. Aceso em 23 set 2018.

CREPALDI, Silvio Aparecido. Contabilidade gerencial: teoria e prática. 9 ed. São Paulo: Atlas, 2013. FERNANDES, Daniela Pereira. Controladoria estratégica: uma nova forma de pensar e planejar o futuro das empresas. Disponível em: < https://www.treasy.com. br/blog/controladoria-estrategica/ >. Acesso em 29 set 2018.

FIGUEIREDO, Sandra, Caggiano, Paulo Cesar. Controladoria: teoria e prática. 5 ed. São Paulo: Atlas, 2017.

GUSMÃO, Sandra Soares; BATISTA, Igor Velozo Colares. Balanced scorecard (BSC): analise de sua implementação e utilização em uma empresa farmacêutica no norte de minas gerais. Disponível em:< http://www.congressocfc.org.br/hotsite/trabalhos_1/2010.pdf >. Acesso em 18 ago 2018.

KAPLAN, Robert S. e NORTON, David P. A estratégia em ação: balanced scorecard. 1 ed. São Paulo: Campus 1997.

LAKATOS, Eva Maria, MARCONI, Mariana de Andrade. Técnicas de pesquisa: planejamento e execução de pesquisas, amostragens e técnicas de pesquisa, elaboração, análise e interpretação de dados. 7 ed. São Paulo: Atlas, 2009. 
MINAYO, Maria Cecília de Souza, GOMES, Suely Ferreira Deslandes Romeu. Pesquisa Social: teoria, método e criatividade. 31 ed. Petrópolis: Vozes, 2012.

MOSIMANN, Clara Pellegrinello, FISCH, Silvio. Controladoria: seu papel na administração de empresas. 1 ed. Florianópolis: UFSC, 1993.

OLIVEIRA, Djalma Pinho Rebouças. Planejamento estratégico: conceito, metodologia e prática. 16 ed. São Paulo: Atlas 2001.

OLIVEIRA, Luís Martins de, PEREZ JUNIOR, José Hernandez, SILVA, Carlos Alberto dos Santos. Controladoria Estratégica: textos e casos práticos com solução. 11 ed. São Paulo: Atlas, 2015.

OLIVEIRA, Wallace. Entenda em detalhes o que é o Balanced Scorecard. Disponível em:< http://www.venki.com.br/blog/o-que-e-balanced-scorecard/ > . Acesso em 23 set 2018.

PADOVEZE, Clóvis Luís. Controladoria básica. 2 ed. São Paulo: Cegage Learning, 2010.

Controladoria estratégica e operacional. 3 ed. São Paulo: Cengage Learning, 2012.

Perspectivas do Balanced Scorecard. Disponível em < https://www.google.com/search? $\mathrm{q}=$ perspectivas+do+balanced+scorecard\&source $=1 \mathrm{nms} \& \mathrm{tbm}=\mathrm{isch} \& \mathrm{sa}=\mathrm{X} \& \mathrm{ved}=0 \mathrm{ahUKEwjN1 \textrm {q }} \mathrm{u} 48$ _ dAhXEkZAKHZVeBXYQ_AUICigB\&biw=1366\&bih=626\#imgrc=HaGupzvRRzrO7M>. Acesso em 22 set 2018.

RAMOS, Darvidson. O que é BSC (Balanced Scorecard). Disponível em: < http://www.blogdaqualidade.com.br/o-que-e-bsc-balanced-scorecard/ >. Acesso em 18 set 2018.

SCHMIDT, Paulo e SANTOS, José Luiz. Fundamentos da controladoria. 1 ed. São Paulo: Altas, 2009.

SCHMIDT, Paulo, SANTOS, José Luiz e MARTINS, Marco Antônio dos Santos. Manual de controladoria. 1 ed. São Paulo: Atlas, 2014.

TAKAHASHI, Adriana Roseli Wunsch, et all. Pesquisa qualitativa em administração: fundamentos, métodos e usos no Brasil. 1ed. São Paulo: Atlas, 2013.

WAGNER, Diego. Gestão estratégica para grandes projetos: como executar e controlar. Disponível em: <https://meetime.com.br/blog/gestao-empresarial/o-que-gestao-estrategica/ >. Acesso em 15 set 2018.

\section{Como citar este artigo (Formato ABNT):}

LACERDA, Ana Carla Dias de; MACEDO, Maria Erilúcia Cruz. Controladoria Estratégica como Suporte a Gestão e Competitividade: Uma perspectiva sobre o Balanced Scorecard. Id on Line Rev.Mult. Psic., 2019, vol.13, n.43, p. 648-669. ISSN: 1981-1179.

Recebido: 23/11/2018;

Aceito: $26 / 11 / 2018$ 